\title{
Experimental study on the coefficient of lateral earth pressure in unsaturated soils
}

\author{
Ali Pirjalili ${ }^{1, a}$, Aliakbar Golshani ${ }^{2}$ and Ali Mirzaii ${ }^{3}$ \\ ${ }^{1}$ M.Sc. Student, Department of Soil and Foundation Engineering, Faculty of Civil and Environmental Engineering, Tarbiat Modares \\ University, Iran \\ ${ }^{2}$ Assistant Professor, Department of Soil and Foundation Engineering, Faculty of Civil and Environmental Engineering, Tarbiat Modares \\ University, Iran \\ ${ }^{3}$ Assistant Professor, Department of Civil Engineering, Faculty of Engineering, University of Kashan, Iran
}

\begin{abstract}
Accurate measurement of lateral earth pressure coefficient, $k$, is a key step in any geotechnical investigation. Since conventional approaches for obtaining this value leads to high risk of uncertainty in the results, this paper introduces a new experimental approach for measuring the value of $k$, particularly in unsaturated soils. Details of the new instrument designed for this purpose is provided in the manuscript, which is capable of obtaining $k$ value of unsaturated soils in a range of matrix suction or degree of saturation. Finally, some test results are presented that examine the accuracy of the novel apparatus in order to measure the coefficient of lateral earth pressure in unsaturated soils.
\end{abstract}

\section{Introduction}

Lateral earth pressure is a crucial issue, which affects obviously on many geotechnical applications analyses such as; underground structures, slope stability and retaining walls. Generally, lateral earth pressure refers to the coefficient of lateral earth pressure, $k$; therefore, obtaining an accurate and reliable values is necessary. Typically, simplifying assumptions have been considered in calculation of this factor by using conventional equations; however, experimental studies provide better estimations of true soil behaviour.

Conventional soil mechanic principles are based on saturated mode of soil. Also, previous studies for evaluating of at-rest lateral earth pressures coefficient, $k_{0}$, were based on this suggestion. (Terzaghi 1920; Chi-in 1957; kjellman 1936; Okochi and Tatsuoka 19884; lo and Chu 1990; Chu et al.1992; Mesri and Hayat 1993; Chu and Gun 2004; Northcutt and Wijewickreme 2013).[1-9]

In spite of the fact that most analysis are based on saturated soil mechanic principles, the major part of the earth land are composed of unsaturated soils. As mechanical properties of saturated and unsaturated soils are obviously different, it is necessary to study about $k$ value in unsaturated mode.

Because of test procedure complexity, there are a few experimental studies which seeking $k$ coefficient in unsaturated soils. Zhang et al. (2009) have performed a series of tests to evaluate $k_{0}$ in a recompacted expansive soil by a stress-path triaxial system. They showed that $k_{0}$ increasing by increasing in saturation degree of soil[10].

\footnotetext{
alipirjalili@yahoo.com
}

In addition, Sr. Oh et al. (2013) have used a suctioncontrolled $k_{0}$ consolidation triaxial test procedure to evaluate $k_{0}$ in two different soils. Results of this study show decreasing in $k_{0}$ value by increasing matrix suction. Recently, Li et al. (2014) have carried out a centrifugal test on a clayey soil to examine $k_{0}$ and they observed $k_{0}$ increasing by saturation degree increase. In this study, it proved that $k_{0}$ value in unsaturated soil is less than that obtained in saturated soil.[11, 12]

Nowadays available information about the coefficient of lateral earth pressure behavior in unsaturated soils is limited to some experimental data that mainly focused on $k_{0}$, however at-rest condition exists scarcely in geotechnical applications. This paper introduces a suction-controlled approach by using a new device whereby $k$ could be evaluated in at-rest state.

\section{Apparatus Feature}

Fig. 1 shows a schematic of test procedure designed to evaluate $k$ in a suction-controlled system. To this end, a new device has been designed and built in Tarbiat Modares University for the first time.

Test system consists of four main parts; ring device, loading system, data acquisition, and an automatic volume change. To measure the coefficient of lateral earth pressure, lateral pressure measurement was needed in order to calculate vertical overburden pressure changes into lateral pressure rate. A Ring device was used for measuring lateral pressure. Fig.2 demonstrates its components. As shown, the specimen ring is a flexible 


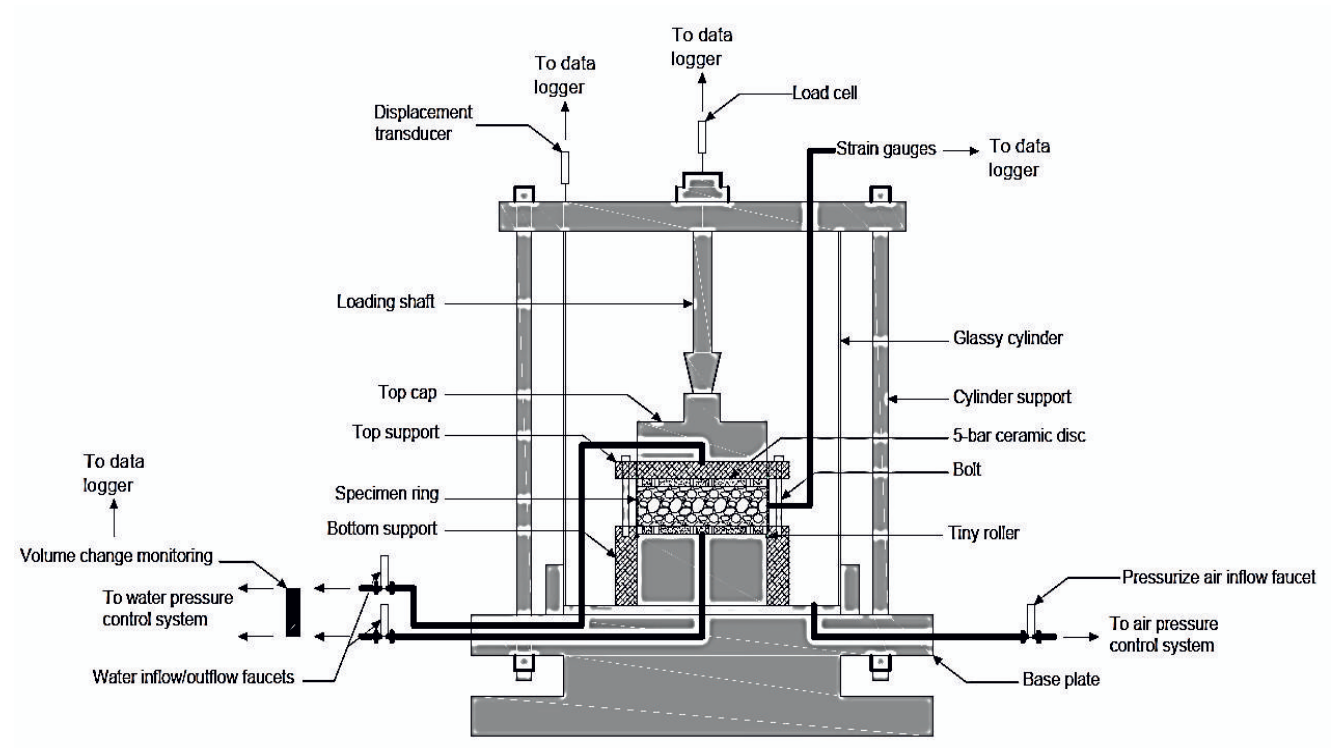

Figure 1. Test Procedure

thin ring by $1 \mathrm{~mm}$ thickness, $20 \mathrm{~mm}$ sample height, and $70 \mathrm{~mm}$ inner diameter.

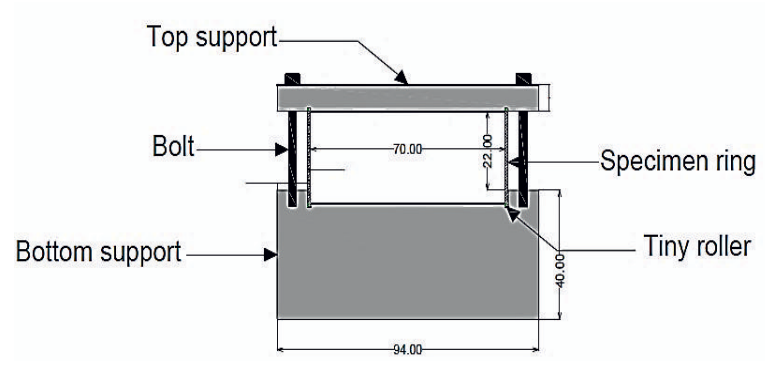

Figure 2. Ring Device Components

The ring device was placed in a triaxial chamber and it used for measuring lateral pressure of soil specimens (Fig. 1). In order to fix the specimen ring in axial direction, two supports have been used and ring leans on some tiny rollers located inside the top and bottom supports. In addition, top and bottom supports were fixed to each other moderately. Three strain gauges installed on ring outer wall in order to monitor lateral strain, as shown in Fig. 3 .

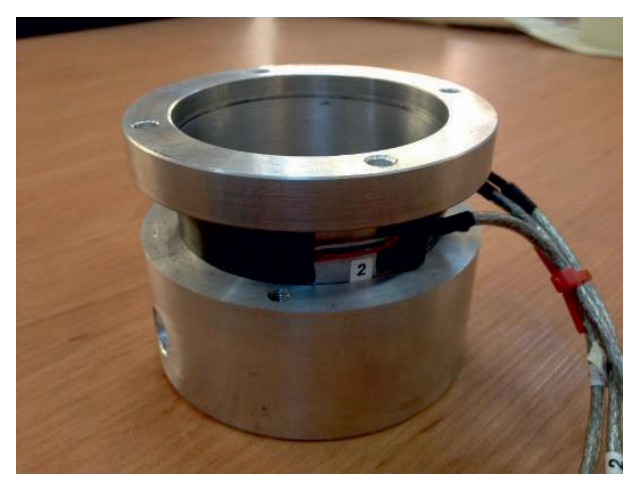

Figure 3. Ring Device

For interpreting recorded data, strain gauges installed on specimen ring were calibrated by installing specimen ring between two caps on top and bottom of ring, which were tightened to each other moderately. To calibrate specimen ring, several defined pore air pressures were applied inside the ring and strain gauges records allocated to applied pressure.

This process was repeated three times in seven pressure points and a calibration factor was reported for every cycle. Fig. 4 shows results of tests performed for calibration procedure. A fit linear relationship was observed between results for every cycle, as shown in Fig.4. Consequently, an average factor from three cycles was reported as calibration factor. It should be mentioned that recorded data in main test were less than 0.2 (in data output unit, as shown in Fig. 4), which data demonstrated sufficient adjacency to each other.

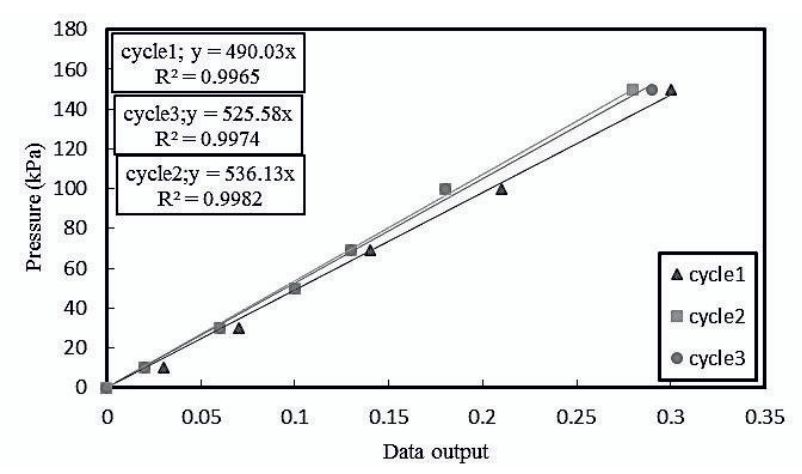

Figure 4. Calibration Results

\section{Material and Test procedure}

Some validation tests have been performed to check accuracy of proposed approach. In this study, Firouzkouh clay was chosen in order to examine the dependency of $k$ value on matrix suction and initial void ratio in unsaturated soil. The mechanical properties of this soil summarized in Table 1. Other properties of Firouzkouh clay investigated in a series of experimental studies by Mirzaii and Yasrobi in 2012. (2012a, b). [13, 14] 
The specimens were compacted in two diverse initial void ratios, 0.71 and 0.92 . Moreover, three different matrix suctions were defined to apply on the soil specimens in order to examine dependency of $k$ value on initial void ratio and matrix suction in same time.

Table 1. Soil Mechanical Property

\begin{tabular}{cc}
\hline Property & amount \\
\hline Specific Gravity & 2.75 \\
Maximum dry unit weight, $\mathrm{kN} / \mathrm{m}^{3}$ & 18.06 \\
Liquid limit \% & 30 \\
Plastic index \% & 9 \\
Percentage $<4.75 \mathrm{~mm}$ & 100 \\
Percentage $<75 \mu \mathrm{m}$ & 88.7 \\
Percentage $<2 \mu \mathrm{m}$ & 20 \\
Optimum water content $\%$ & 14.1 \\
Soil classification & $\mathrm{CL}$ \\
\hline
\end{tabular}

The soil specimen was wetted in optimum water content and it was mounted into the triaxial chamber. The coefficient of at-rest lateral earth pressure was measured in 10,50 and $90 \mathrm{kPa}$ of matrix suction. To achieve that, the pore air pressure was increased gradually from 0 to $300 \mathrm{kPa}$ and after that, the pore water pressure was increased to the defined pressures $(290,250$ and $210 \mathrm{kPa})$ in which calculated for desired matrix suctions $(10,50$ and $90 \mathrm{kPa}$ ). To achieve to the equalization stage, the specimen has been kept under this condition for about 18$24 \mathrm{hrs}$ to wet. By allowing water and air draining in samples, matrix suction were constant during the all tests.

Within wetting stage, water inflow to specimen was observed for all specimens. The specimens' compression during the wetting stage was controlled by an automatic volume change accurately. The wetting stage considered to be finished when the water inflow rate reaches to a steady mode and water inflow volume remained more-orless constant, as shown in Fig.5.

After equalization stage, the specimen was loaded axially by a static system with a constant rate of $0.5 \mathrm{~mm}$ per minute, which was slow enough for air and water drainage. In a same with equalization stage, in this step allowing water and air drainage kept the matrix suction constant during the test. In addition, using two porous stone in top and bottom of the sample beside low height of each sample, made the drainage process possible. To monitor constancy of matrix suction, the water and air pressure gauges were observed which were constant during the test.

Loading process has been kept running until the measured $k$ attained to a stable condition (this condition normally occurred about $0.4-0.6 \%$ specimen radial strain). As radial strains were not enough to reach to active condition, measured $k$ amounts belong to a state between active and at-rest condition. During the test, matrix suction were remained constant by allowing water and air exceeding to the soil. a

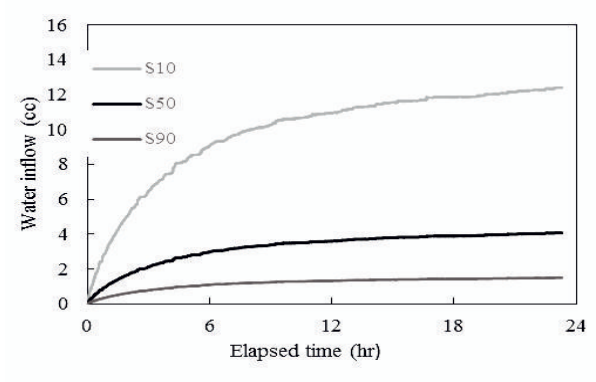

b

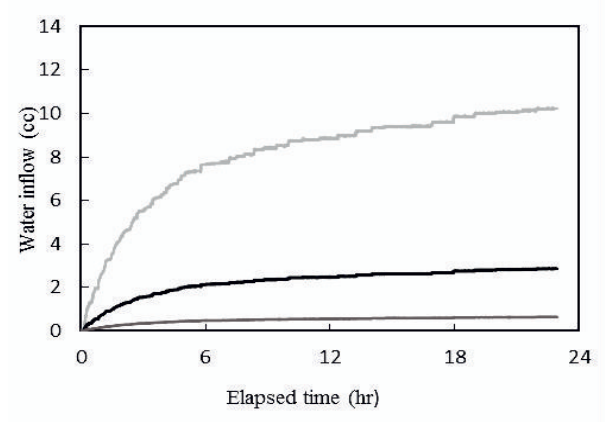

Figure 5. Wetting Stage ( $\left.a: e_{0}=0.71, b: e_{0}=0.92\right)$

\section{Results}

The coefficients of lateral earth pressure values versus specimens' vertical strain were measured during the test and they were demonstrated in Fig.6. This figure presents that $k$ value reached to a steady value in a range of $0.4-$ $0.6 \%$ vertical strain in every soil specimen. Steady $k$ value for each test has been summarized in Table 2 .

Table 2. Final $k$ Amounts

\begin{tabular}{|c|c|c|}
\hline \multirow{3}{*}{$\begin{array}{l}\text { Matrix Suction } \\
\qquad k P a\end{array}$} & \multicolumn{2}{|c|}{ Initial void ratio } \\
\hline & 0.71 & 0.92 \\
\hline & \multicolumn{2}{|c|}{$k$ amount } \\
\hline 10 & 0.411 & 0.481 \\
\hline 50 & 0.391 & 0.455 \\
\hline 90 & 0.371 & 0.429 \\
\hline
\end{tabular}

The $k$ sensitivity to matrix suction changing is demonstrated in Fig. 7 that measured $k$ are plotted versus diverse matrix suctions were applied to the soil for both specimens compacted in 0.71 and 0.92 initial void ratio, respectively. According to this figure, experimental results show that the $k$ values decreased by matrix suction increasing obviously. 

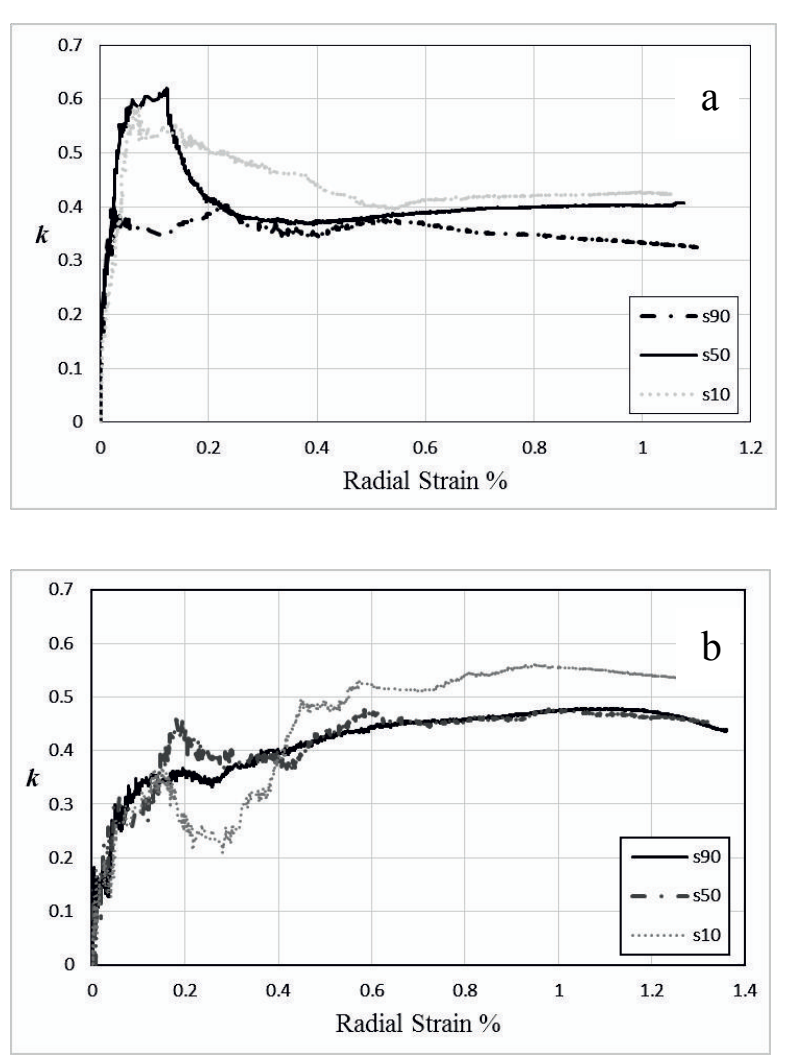

Figure 6. $k$ Amount versus Vertical Strain $\left(a: e_{0}=0.71, b\right.$ : $\left.e_{0}=0.92\right)$

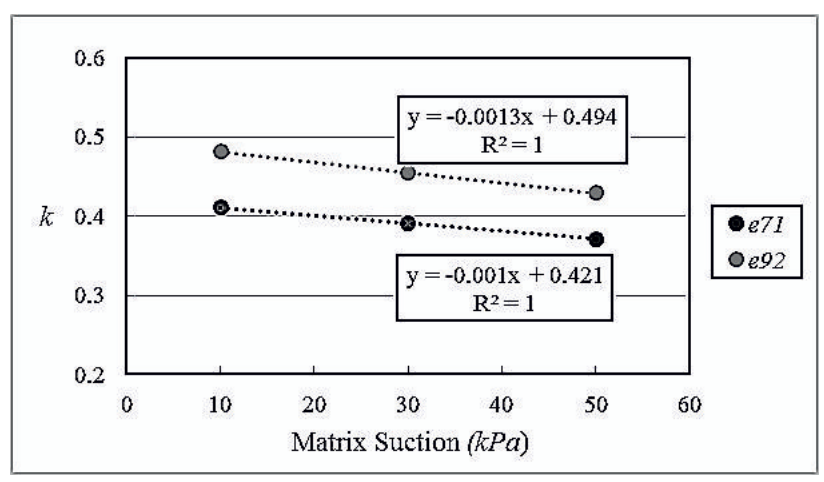

Figure 7. $k$ Changes versus a Range of Matrix Suctions

With regards to Fig.7, dependency of $k$ values to matrix suction appears to be a linear relationship and this behavior was observed in both specimen by 0.71 and 0.92 of initial void ratio. By caparisoning $k$ amount in both soil samples with the initial compaction void ratio of 0.71 and 0.92 (see Fig. 7), it could be concluded that obtained $k$ in soil by 0.71 initial void ratio is less than that in specimen compacted in 0.92 void ratio initially. Therefore, $k$ value for looser soil is more than that in denser one, which this behavior has also been observed in saturated soils. (Chu and Gun 2004)[8]

\section{Conclusion}

In order to examine dependency of the coefficient of lateral earth pressure, $k$, on initial void ratio and matrix suction in unsaturated soil, a new method has been introduced in this paper. To achieve this goal, a new ring device has been designed and built in Tarbiat Modares University. In order to validate this new method, some tests have been performed on a clayey soil and results show that this method is reliable enough to measure $k$ amount in unsaturated soils. In addition, results have been interpreted in manuscript showed that $k$ amount decreased by increasing matrix suction in a linear relationship. This phenomena has been observed in both specimen compacted in 0.71 void ratio initially and 0.92 . Furthermore, $k$ values in soil specimens by 0.71 initial void ratio are more than that in sample by 0.92 initial void ratio. The measured $k$ amounts have been belonged to a state between active and at-rest condition.

\section{References}

1. K.v. Terzaghi, Eng. News-Rec., 85(14), 632-637 (1920)

2. H. Chi-in, China Civil Eng. J., 2, 002 (1957)

3. W. Kjellman, Proceedings of the 1st International Conference on Soil Mechanics and Foundation Engineering. (1936)

4. Y. Okochi, and F. Tatsuoka, Soil and Fund., 24(3), 52-68 (1984)

5. J. Chu, and S.C.R. Lo, On the implementation of strain path testing, University College, Australian Defence Force Academy, University of New South Wales (1990)

6. J. Chu, S.C.R. Lo, and I.K. Lee, J. Geotech. Eng.ASCE, 118(2), 191-208 (1992)

7. G. Mesri, and T. Hayat, Can. Geotech. J., 30(4), 647666 (1993.)

8. Chu, J. and C. Gan, Geotechnique, 54(4), 285-288 (2004)

9. S. Northcutt, and D. Wijewickreme, Can. Geotech. J., 50(5), 457-466 (2013)

10. R. Zhang, J.L. Zheng, and H.P. Yang, Recent Advancement in Soil Behavior, in Situ Test Methods, Pile Foundations, and Tunneling@s selected Papers from the 2009 GeoHunan International Conference, ASCE ( 2009)

11. S. Oh, et al., J. Geotech. Geoenviron., 2012.

12. G.E.J. Poinern, A Laboratory Course in Nanoscience and Nanotechnology, CRC Press (2014)

13. A. Mirzaii, and S.S. Yasrobi, Transport porous med., 95(3), 497-505.(2012)

14. A. Mirzaii, and S. Yasrobi, Géotechnique Lett., 2(October-December), 193-198 (2012) 